\title{
The influence of cetane-detergent additives into diesel fuel increased to $10 \%$ (V/V) of RME content on energy parameters and exhaust gas composition of a diesel engine
}

To avoid the negative effects of increasing the amount of RME in the diesel fuel (to 10\%), three different additive packages were used: stabilising, cleaning, and increasing the cetane number with different concentrations. The tests were carried out using a 4-cylinder, turbocharged 1.9 TDI engine from VW. The tests were carried out for 4 fuels (comparative fuel with a content of 7\% RME and 3 test fuels with a content of 10\% RME, differing in the content of the additive package. It was found that each of the 3 additive packages used does not have a significant impact on fuel consumption. However, a different effect of the tested additives on the composition of exhaust gases was observed. The first package had a slight effect on reducing the $N_{x}$ concentration in the exhaust, but only for small engine loads. On the other hand, the second additive pack worked more effectively only at higher engine loads (in relation to the reduction of $\mathrm{NO}_{x}$ concentration in the exhaust gases). In the third packet, the amount of the cetane additive was doubled (compared to the second packet). Then, the reduction in the $\mathrm{NO}_{x}$ concentration in the exhaust gas by 3-8\% was obtained with reference to the comparative fuel.

Key words: cetane-detergent additives, RME, exhaust gas composition, diesel engine

\section{Introduction}

According to EU preferences, for well-known reasons, the aim is to increase the rapeseed methyl ester (RME) content in the diesel fuel standard. Currently (2019) the mandatory RME add-on to diesel fuel, which is sold at petrol stations in Europe, is 7\%. The fuel used in the tests contained $10 \%$ of RME. Unfortunately, however, an increase in the amount of methyl esters of vegetable oils is related to i.e. a decrease in the stability of such fuel during storage, increased pollution of the combustion chamber and fuel injector, and increased $\mathrm{NO}_{\mathrm{x}}$ concentration in the engine exhaust. Then the increase in $\mathrm{NO}_{\mathrm{x}}$ emissions in the exhaust gases is mainly the result of the influence of RME on the elongation of the self-ignition delay and what is connected with the increase in the combustion dynamics and consequently the maximum combustion temperature. Therefore, to avoid the mentioned negative effects of increasing the amount of RME in the fuel (to 10\%), three different additive packages were used: stabilising, cleaning, and increasing the cetane number with different concentrations. The tests were carried out using a 4-cylinder, turbocharged 1.9 TDI engine from VW. The tests were carried out for 4 fuels (comparative fuel with a content of $7 \%$ RME and 3 test fuels with a content of $10 \% \mathrm{RME}$, differing in the content of the additive package). For all the fuels, the measurements were carried out at constant engine speed and 6 engine loads.

\section{Characteristics of used and tested fuels}

Three Innocet ${ }^{\circledR}$ detergent-dispersing packages (A, B, and C) were used. The B10 diesel fuel (10\% (by vol.) of RME), whose physico-chemical characteristics are shown in Table 1, was enhanced with the $\mathrm{A}, \mathrm{B}$, and $\mathrm{C}$ Innocet ${ }^{\circledR}$ packages in the quantity of $1,500 \mathrm{mg} / \mathrm{kg}$. Such enhanced $\mathrm{B} 10$ diesel fuel had cetane number equal to 58 . The Innocet $^{(B} \mathrm{A}, \mathrm{B}$, and C packages contained $50 \mathrm{mg} / \mathrm{kg}$ of a commercial detergent-dispersing additive and differed by the level of dosing of the stabilizers taking synergistic part in creation of free radicals in the area of low-temperature and indirect oxidation of the B10 diesel fuel. In this manner, 4 fuels were created, which then underwent engine tests:

- TM/134/18 - comparative fuel B7 (7\% (V/V) RME)

- TM/135/18 - B10 fuel with the Innocet ${ }^{\circledR}$ A package

- TM/136/18 - B10 fuel with the Innocet ${ }^{(\mathbb{B}}$ B package

TM/154/18 - B10 fuel with the Innocet ${ }^{\circledR} C$ package

Table 1. Physical and chemical properties of B10 diesel fuel

\begin{tabular}{|c|c|c|}
\hline Property & Unit & Results \\
\hline Cetane number & - & $52.3 \pm 3.0$ \\
\hline Cetane number derivative & - & $53.41 \pm 0.18$ \\
\hline Cetane index & - & $55.0 \pm 0.8$ \\
\hline Density at $15^{\circ} \mathrm{C}$ & $\mathrm{kg} / \mathrm{m}^{3}$ & $830.4 \pm 0.4$ \\
\hline PAH content & $\%(\mathrm{~m} / \mathrm{m})$ & $1.1 \pm 0.5$ \\
\hline Sulfur content & $\mathrm{mg} / \mathrm{kg}$ & $4.9 \pm 1.2$ \\
\hline Manganese content & $\mathrm{mg} / \mathrm{l}$ & $<0.5$ \\
\hline Flash point & ${ }^{\circ} \mathrm{C}$ & $60.5 \pm 2.5$ \\
\hline $\begin{array}{l}\text { Carbon residue } \\
\text { (on } 10 \% \text { distillation residue) }\end{array}$ & $\%(\mathrm{~m} / \mathrm{m})$ & $0.016 \pm 0.012$ \\
\hline Water content & $\mathrm{mg} / \mathrm{kg}$ & $60 \pm 38$ \\
\hline Total contamination & $\mathrm{mg} / \mathrm{kg}$ & $20.5 \pm 5.4$ \\
\hline Cooper strip corrosion $\left(3 \mathrm{~h}\right.$ at $\left.50^{\circ} \mathrm{C}\right)$ & $\begin{array}{l}\text { corrosion } \\
\text { rate }\end{array}$ & 1 \\
\hline Oxidation stability $\left(\mathrm{g} / \mathrm{m}^{3}\right)$ & $\mathrm{g} / \mathrm{m}^{3}$ & $8 \pm 7$ \\
\hline $\begin{array}{l}\text { Oxidation stability }\left[110^{\circ} \mathrm{C}\right] \text { (Ranci- } \\
\text { mat) }\end{array}$ & $\mathrm{h}$ & 23.1 \\
\hline Lubricity, wear scar diameter at $60^{\circ} \mathrm{C}$ & $\mu \mathrm{m}$ & $165 \pm 73$ \\
\hline Viscosity at $40^{\circ} \mathrm{C}$ & $\mathrm{mm}^{2} / \mathrm{s}$ & $2.730 \pm 0.022$ \\
\hline $\begin{array}{l}\text { Distillation } \\
\%(\mathrm{~V} / \mathrm{V}) \text { recovered at } 250{ }^{\circ} \mathrm{C} \\
\%(\mathrm{~V} / \mathrm{V}) \text { recovered at } 350{ }^{\circ} \mathrm{C} \\
95 \%(\mathrm{~V} / \mathrm{V}) \text { recovered at }\end{array}$ & $\begin{array}{l}\%(\mathrm{~V} / \mathrm{V}) \\
\%(\mathrm{~V} / \mathrm{V}) \\
{ }^{\circ} \mathrm{C}\end{array}$ & $\begin{array}{c}36.8 \pm 1.9 \\
93 \pm 1.9 \\
355.9 \pm 6.6\end{array}$ \\
\hline $\begin{array}{l}\text { Fatty acid methyl ester (RME) con- } \\
\text { tent }\end{array}$ & $\%(\mathrm{~V} / \mathrm{V})$ & $9.9 \pm 0.5$ \\
\hline Ash content & $\%(\mathrm{~m} / \mathrm{m})$ & $<0.001$ \\
\hline
\end{tabular}

\section{Characteristics of laboratory for engine tests}

The engine tests of the fuels in question were performed at the Internal-Combustion Engines Laboratory of the Insti- 
tute of Motor Vehicles and Internal-Combustion Engines of the Cracow University of Technology.

Tests for each of the tested fuels were carried out using a 4-cylinder diesel engine, type 1.9 TDI (AJM version), made by $\mathrm{VW}$, whose technical characteristics are shown in Table 2.

Each of the 4 fuels made it possible to determine, on the background of the load characteristics of the engine (at the rotational speed corresponding to the maximum torque), 5 groups of engine parameters:

- energy parameters of engine (fuel consumption, total efficiency of diesel engine),

- composition of exhaust gases (concentration of $\mathrm{CO}$, THC, $\mathrm{NO}_{\mathrm{x}}$ and smoke),

- parameters of engine systems (e.g. start of fuel injection, temperature and pressure of air after turbocharger, temperature of exhaust gases, percent of EGR),

- parameters of indicator diagrams (e.g. start of selfcombustion, maximum rate of combustion pressure, maximum of combustion pressure),

- parameters of heat release diagrams (e.g. maximum of kinetic and diffusion heat release, end of combustion).

Table 2. Technical parameters of VW 1.9 TDI (type AJM)

\begin{tabular}{|l|c|}
\hline type of fuel ignition & self-ignition \\
\hline cylinder layout & in-line \\
\hline the number of cylinders & 4 \\
\hline piston diameter & $79.5 \mathrm{~mm}$ \\
\hline piston stroke & $95.5 \mathrm{~mm}$ \\
\hline engine displacement & $1,896 \mathrm{~cm}^{3}$ \\
\hline geometric compression ratio & 18 \\
\hline cylinders work order & $1-3-4-2$ \\
\hline rated gross power & $85 \mathrm{~kW}$ \\
\hline rated engine speed & $4,000 \mathrm{rpm}$ \\
\hline maximum engine speed & $4450 \mathrm{rpm}$ \\
\hline maximum engine torque & $285 \mathrm{Nm}$ \\
\hline rot. speed of maximum torque & $2,000 \mathrm{rpm}$ \\
\hline volume of the engine cooling system & $6.1 \mathrm{dm}$ \\
\hline volume of the engine oil system & $4.4 \mathrm{dm}$ \\
\hline lubricating oil pressure & $0.11-0.41 \mathrm{MPa}$ \\
\hline fuel supply system & unit injectors \\
\hline max. pressure of fuel injection & $20 \mathrm{MPa}$ \\
\hline
\end{tabular}

In order to measure and analyze the parameters of the engine fuelled sequentially by tested fuels was used part of the measuring systems, which are equipped laboratory of Cracow University of Technology. The study was carried out using the popular VW 1.9 TDI engine in the AJM version (with unit injectors), popular in Europe, in passenger cars and light commercial vehicles. This article describes the influence of engine load (at max torque speed 2000 $\mathrm{rpm}$ ) on the basic engine parameters and exhaust composition. In the study were used Schenk engine dynamometer, AVL Fuel Balance (for measure of fuel consumption) and AVL Bench Emission System CEB II for measuring the concentration of gaseous components. In addition, the air temperature collected by the engine, the air temperature behind the turbocharger, behind the inter-cooler and into the intake manifold (behind the EGR valve) were measured. The exhaust gas temperature was measured before and after the turbocharger. For comprehensive analysis, the impact of the engine load on the boost pressure and the start of fuel injection were measured. In the second part of the article, the AVL Indimeter 617D was also used to determine and analyze the fast-changing pressure in the engine cylinder (as a function of the engine crankshaft rotation angle) and to calculate the rate of heat release.

\section{Experimental}

\subsection{Energy parameters of the engine}

Because the impact of engine load on most of the analyzed parameters is much higher than the impact of the tested fuel additives, a linear load characteristics analysis is very difficult. Therefore, in order to perform a more accurate analysis, bar graphs were prepared, based on crosssections of load characteristics, of all parameters for low, medium, and high load of the engine $(50 \mathrm{Nm}, 150 \mathrm{Nm}$, and $250 \mathrm{Nm}$ ). As a result, with changed ranges of the value of specific parameters (for different loads), it was easier to analyze the impact of the tested fuels on the analyzed parameter.

The characteristics of the fuels used in the tests are shown in item 2 of this paper.

The basic energy parameter of the engine (at a constant rotational speed and engine load) is hourly fuel consumption $(\mathrm{Gpal}[\mathrm{kg} / \mathrm{h}])$ - Fig. 1.

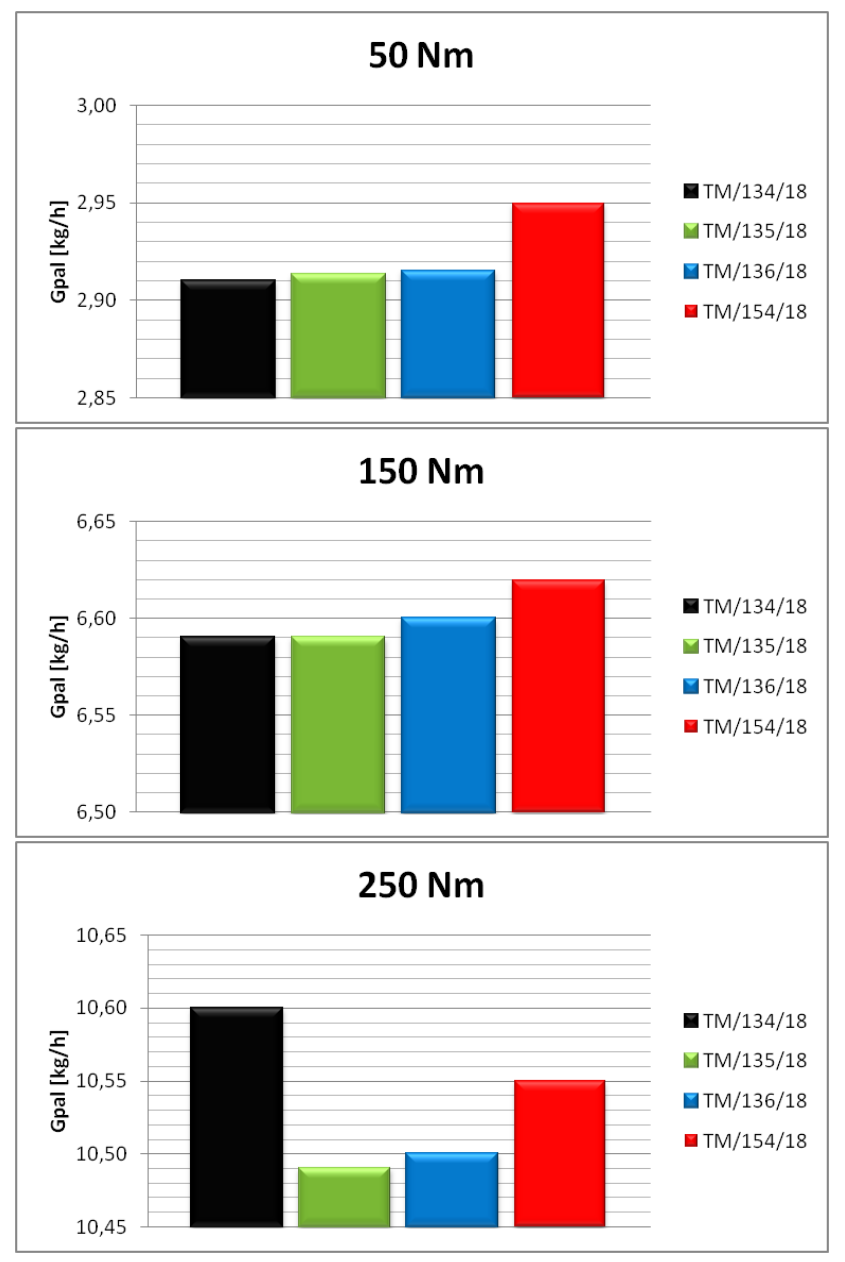

Fig. 1. Hourly fuel consumption in selected duty points of the engine for the four tested fuels 
At low and medium engine load, no beneficial impact of the fuels with special additive packages (TM/135/18, $\mathrm{TM} / 136 / 18$, and $\mathrm{TM} / 154 / 18$ ) was identified, compared to the reference fuel (TM/134/18). The measured difference between the values $G_{p a l}$ in this range of engine load is equal to only approximately $1 \%$. The situation is slightly different in the case of a high engine load when the hourly fuel consumption is slightly lower for all fuels with a special additive packages (TM/135/18, TM/136/18, and TM/154/18)) compared to the TM/134/18 fuel. However, the change is equal to approximately $1 \%$. The relevant additives in principle are supposed to influence the course of the combustion process, including the speed of kinetic and diffusive combustion in the engine chamber; consequently, their influence will be visible mostly in the composition of the exhaust gas, which is discussed in the next chapter.

Because the measurements were conducted at a constant rotational speed of the engine, at constant engine load the percentage changes of the hourly and unit fuel consumption and of the general efficiency of the engine must be the same. The conclusions of the analysis of the impact of engine load on the hourly and unit fuel consumption and on the general efficiency of the engine are certainly the same as the conclusions from the analysis of the hourly fuel consumption for the tested fuels.

\subsection{Exhaust gas composition}

From the point of view of the fast-changing processes in a piston combustion engine, as far as combustion gas composition is concerned, the most important are the combustion gas components that are limited during type testing. This group includes carbon oxide $(\mathrm{CO})$, gaseous hydrocarbons (THC), nitrogen oxides $\left(\mathrm{NO}_{\mathrm{x}}\right)$, particulate matter (PM), and non-toxic carbon dioxide $\left(\mathrm{CO}_{2}\right)$.

The principal objective of use of one of the additives in the tested fuels (TM/135/18, TM/136/18, TM/154/18) was to shorten the self-ignition delay $\mathrm{t}_{\mathrm{sp}}$ and, consequently, to reduce the concentration of nitrogen oxides $\left(\mathrm{NO}_{\mathrm{x}}\right)$ in the engine's exhaust gas. In the conditions present in the course of the combustion process in the cylinder of a diesel engine, emission of nitrogen oxides is related most of all to the maximum combustion temperature (to a smaller extent with availability of oxygen and duration of the nitrogen oxidation reaction). Consequently, the shorter the self-ignition delay (the shorter the time of gathering of the fuel dose in the combustion chamber until the self-ignition), the smaller the dose of fuel that undergoes self-ignition, which results in a less dynamic combustion process (lower maximum speed of kinetic combustion) and, consequently, lower maximum combustion temperature, which leads to a lower concentration and emission of $\mathrm{NO}_{\mathrm{x}}$ in the exhaust gas.

On the other hand, a reduction of the self-ignition delay, tsp, of the fuel leads to a reduction of the time of mixing of fuel with air before the fuel self-ignition, which results in incomplete combustion, which in turn increases the emission of particulate matter and smoke opacity of the exhaust gas. At the same time, a reduction of the $t_{\mathrm{sp}}$ shortens the time of gathering of fuel in the combustion chamber before self-ignition, which, as has been mentioned, reduces the maximum and average combustion temperature. A reduction of the combustion temperature leads to combustion of a smaller quantity of soot and PM that have been produced. Consequently, all in all, a reduction of the self-ignition delay of the fuel involves an increased quantity of smoke opacity of the exhaust gas and an increased emission of particulate matter.

Based on the above brief analysis of the mechanisms of occurrence of emission of particulate matter (PM) and nitrogen oxides $\left(\mathrm{NO}_{\mathrm{x}}\right)$, research on various diesel engines tested for years in laboratories worldwide has demonstrated that use of one design or regulation or fuel method, which reduces the self-ignition delay, reduces the emission of $\mathrm{NO}_{\mathrm{x}}$ but, at the same time, increases the emission of PM. This is shown schematically in Fig. 2.

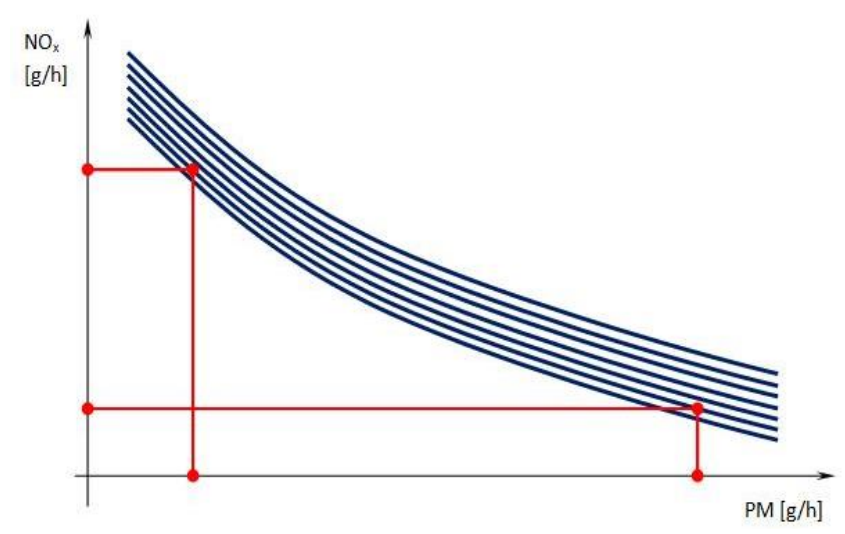

Fig. 2. Diagram of correlation between $\mathrm{NO}_{\mathrm{x}}$ and $\mathrm{PM}$ emissions

If design and regulation methods are used for the engine or for fuel additives, usually several procedures are performed that simultaneously reduce the emission of $\mathrm{NO}_{\mathrm{x}}$ and PM (including smoke opacity D) in exhaust gas from a diesel engine.

Figure 3 shows the impact of engine load on concentration of nitrogen oxides $\left(\mathrm{NO}_{\mathrm{x}}\right)$ in exhaust gas of an engine supplied, consecutively, with the four tested fuels TM/134/18, TM/135/18, TM/136/18, and TM/154/18. The data shown in Fig. 3 indicates that at a low engine load use of fuels with a special additive package does not have a significant impact on the concentration of $\mathrm{NO}_{\mathrm{x}}$ in the exhaust gas. The observed differences between the concentration of $\mathrm{NO}_{\mathrm{x}}$ for the fuels used are equal to just several ppm and are within the range of repeatability of the operation of the engine and the measurement accuracy. In the quantitative sense, the situation is similar for the average engine load; however, in this operation range the concentration of nitrogen oxides in the exhaust gas is systematically only a little lower for fuels with the special additives packet (TM/135/18, TM/136/18, and TM/154/18) compared to the reference fuel (TM/134/18). Only at high engine loads, the impact of one of the fuel additives, TM/154/18, on a reduction of concentration of nitrogen oxides in the exhaust gas compared to other fuels, especially TM/134/18, becomes clearly visible. The difference is $26 \mathrm{ppm}(3.2 \%)$ at the load of $250 \mathrm{Nm}$. For the maximum engine load that has been applied $(280 \mathrm{Nm})$, the difference is as large as $7 \%$.

The intensity of the impact of this type of fuel additives quite often depends on the engine temperature and, consequently, on the engine load. A similar phenomenon is also 
observed when comparing the concentration of $\mathrm{NO}_{\mathrm{x}}$ in exhaust gas of an engine supplied with fuels TM/134/18 and TM/154/18. Only at high engine loads, the concentration of nitrogen oxides in the exhaust gas is significantly lower for the TM/154/18 fuel than for the TM/134/18 fuel.

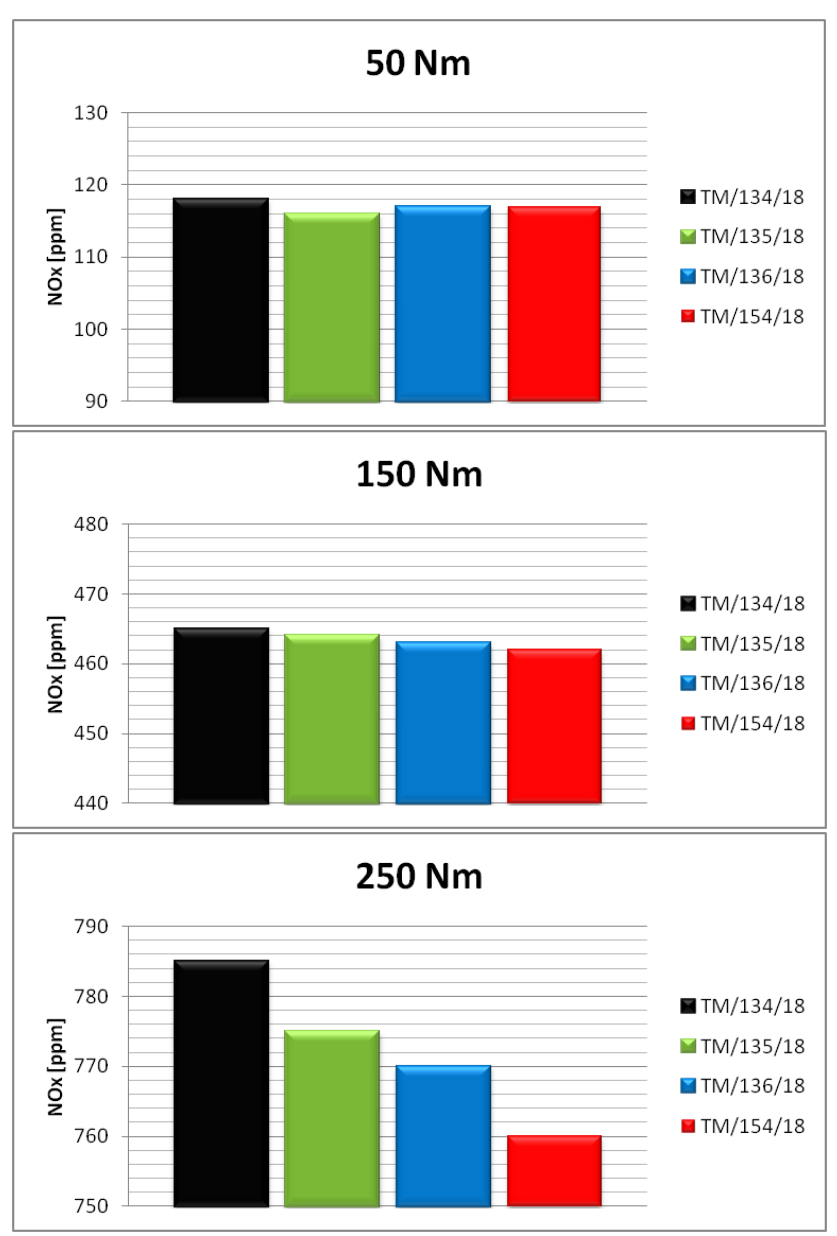

Fig. 3. $\mathrm{NO}_{\mathrm{x}}$ concentration in exhaust gas in selected duty points of the engine for the four tested fuels

Due to the adopted test schedule, emission of particulate matter (PM) was not measured. However, because emission of particulate matter is largely related qualitatively to the smoke opacity of exhaust gas (D), the latter parameter was measured using the Bosch filtration method. The smoke opacity (D) for various loads and for the analyzed fuels is shown in Fig. 4. The accuracy of the measurement of smoke opacity (D) using the Bosch filtration method is equal to $0.05^{\circ} \mathrm{B}$. Thus, one can see that at low and medium engine loads, the fuels used do not have a significant impact on the smoke opacity of the exhaust gas; consequently, they most likely also do not have a significant impact on emission of particulate matter (PM). Qualitatively, the exception is the TM/154/18 fuel, which at all engine loads is characterized by the highest smoke opacity of the exhaust gas. This is particularly evident at high engine load where the difference in the smoke opacity of the exhaust gas of the engine supplied with the comparative fuel TM/134/18 and the fuel $\mathrm{TM} / 154 / 18$ is as much as $0.15^{\circ} \mathrm{B}-$ Fig. 4 . At the same time, one must keep in mind that at that duty point of the engine, that fuel is characterized by the lowest concen- tration of $\mathrm{NO}_{\mathrm{x}}$ in the exhaust gas - Fig. 3. Consequently, the relationship shown schematically in Fig. 2 is confirmed again - the engine or fuel method that reduces the concentration of $\mathrm{NO}_{\mathrm{x}}$ in the exhaust gas also increases the smoke opacity of the exhaust gas. What was also confirmed is that the intensity of impact of the fuel additives usually was greater at higher engine loads.

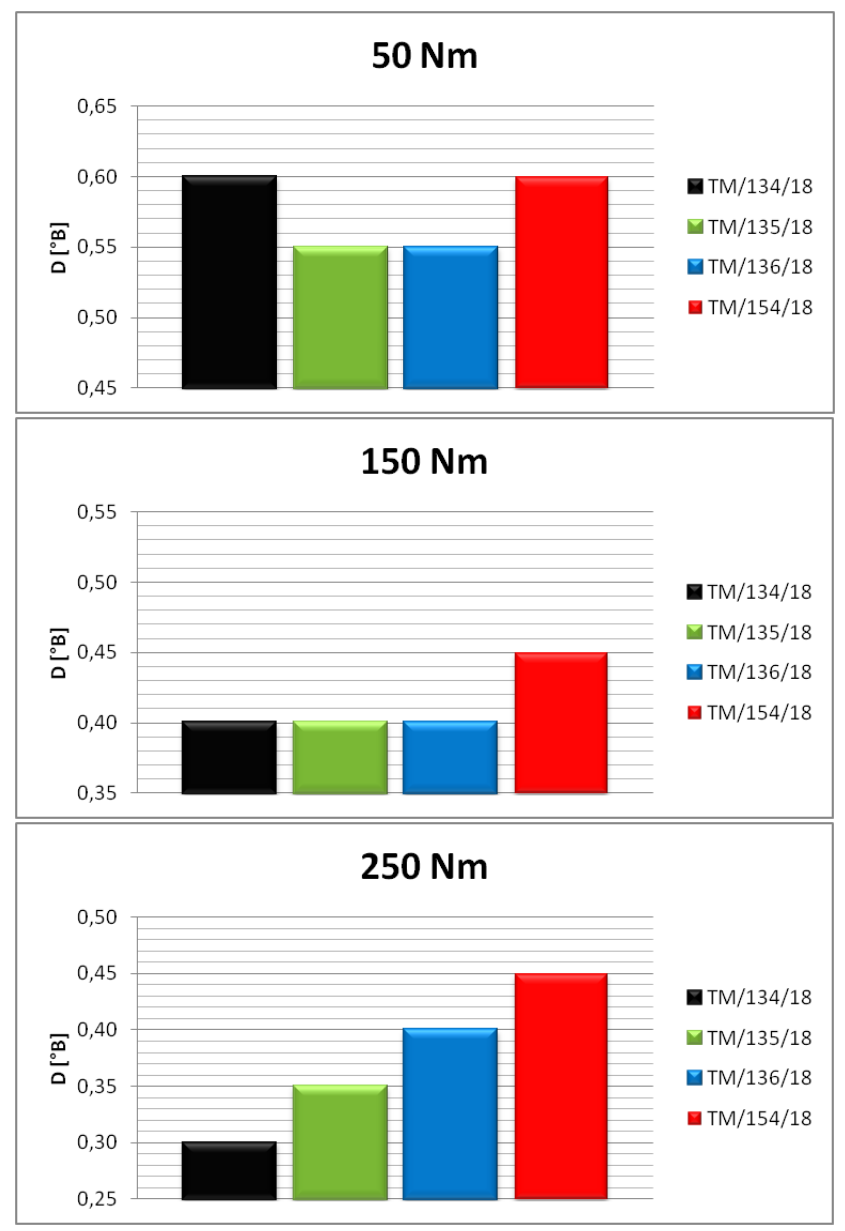

Fig. 4. Smoke opacity of the exhaust gas (D) at selected duty points of the engine for the four tested fuels

Gaseous hydrocarbons (THC) in exhaust gas of a diesel engine are the result of incomplete combustion and their formation, even at sufficient quantities of oxygen, is associated mostly with too low temperature in the fuel combustion zone. Because contemporary diesel engines, including the engine used in the tests, due to the use of various design and regulation measures, are characterized by very low concentrations of THC in exhaust gas (even upstream of the oxidizing catalytic converter) and their concentration is usually equal to several or up to twenty ppm, this component was intentionally not measured during the tests. Moreover, the conversion efficiency of commonly used oxidizing catalytic converters is so high that in reality the concentration of THC in the exhaust gas emitted from diesel engines is insignificant.

From a chemical standpoint, formation of carbon oxide (CO) in combustion conditions in the cylinder of a diesel engine is related to the global shortage of oxygen (homogenous mixture). On the other hand, in a cylinder of a diesel 
engine, formation of CO (even given the global shortage of oxygen) is possible due to local shortage of oxygen around the jets of injected fuel after its self-ignition and in the combustion process (heterogeneous mixture).

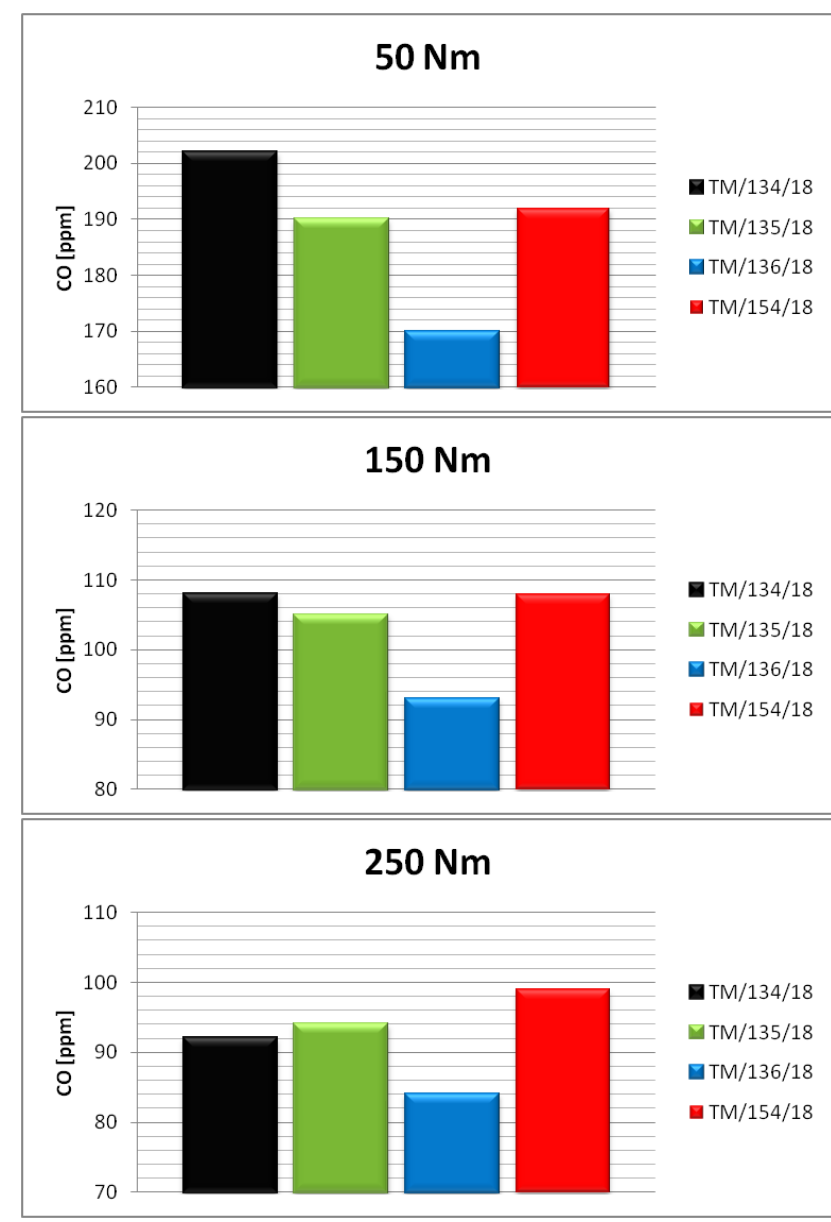

Fig. 5. CO concentration in exhaust gas in selected duty points of the engine for the four tested fuels

The concentration of carbon oxide $(\mathrm{CO})$ presented for the selected fuels in Fig. 5 in the entire range of load of the diesel engine is definitely smaller than in spark-ignition engines, which is due to the range of the value of the air excess $\lambda$ used in diesel engines. Nevertheless, the differences in the $\mathrm{CO}$ concentrations measured in the exhaust gas for the engine used in the tests and for the analyzed fuels are very small. Moreover, as mentioned in the first paragraphs of the chapter, the catalytic (oxidizing) converters that are used make it possible to eliminate those differences. Consequently, in practice, the concentration of THC and $\mathrm{CO}$ upstream of a catalytic converter is not important.

As mentioned in the first paragraphs of this chapter, the concentration of $\mathrm{CO}_{2}$ in the exhaust gas is correlated with the quantity of consumed fuel. However, because the fuel additives affect the hourly consumption of fuel only to a minimum extent (within the limits of repeatability of the operation of the engine - approx. $1 \%$ ), then also the concentration of carbon dioxide $\left(\mathrm{CO}_{2}\right)-$ Fig. 6 - in the exhaust gas of the engine, for the analyzed fuels, shows little difference regardless of the engine load.

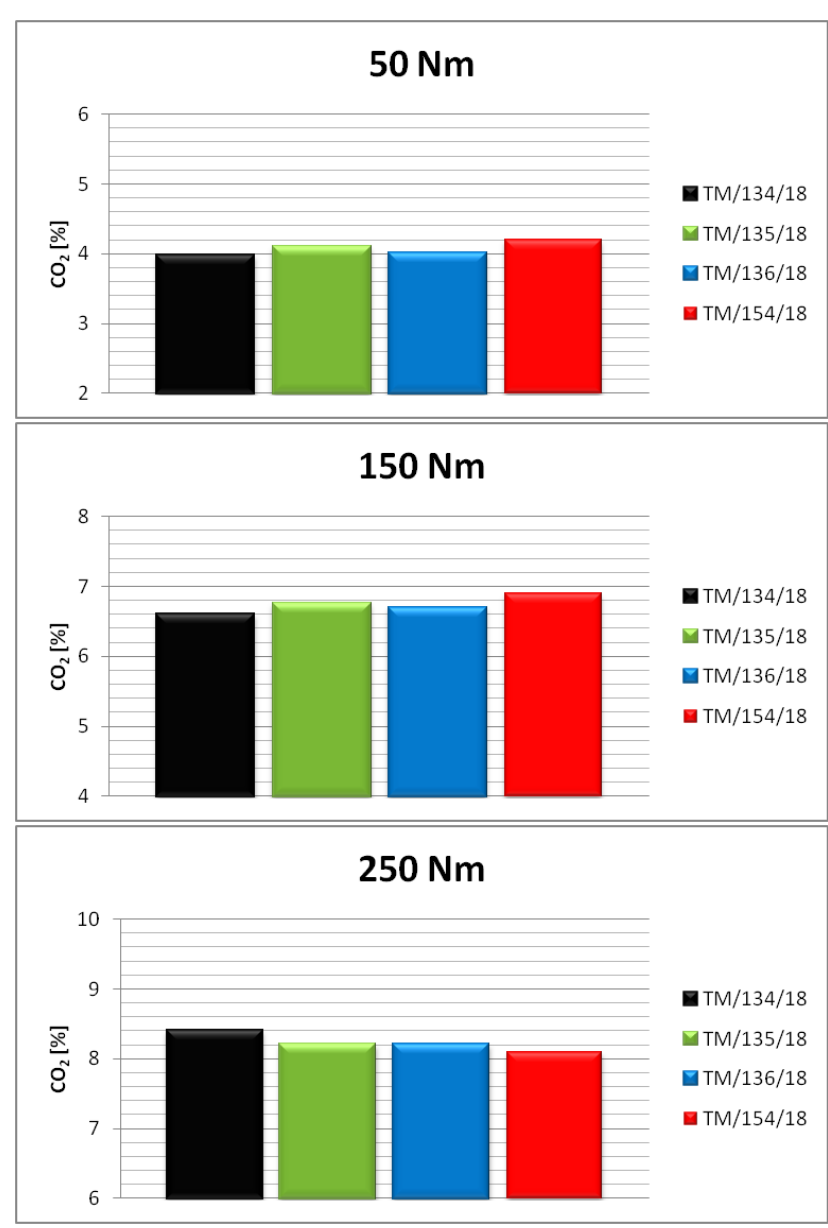

Fig. 6. $\mathrm{CO}_{2}$ concentration in exhaust gas in selected duty points of the engine for the four tested fuels

In order to better understand the impact of the tested fuels on the composition of the exhaust gas, an analysis was performed of the indicator diagrams and the heat release speed in the cylinder of the engine.

In order to better understand the impact of the tested fuels on the composition of the exhaust gas and in order to perform a cause and effect analysis of the occurring phenomena, the measurements were expanded to include indication of the engine cylinder and calculations of the change of the heat release speed as a function of the angle of rotation of the engine crankshaft. A synthesis of the measured parameters is presented in the second article by the same authors, titled "Influence of cetane-detergent additives into diesel fuel with RME content increased to $10 \%$ on the parameters of indicator diagrams and rate of heat release in a diesel engine."

\section{Conclusions}

- The tests that were performed made it possible to draw the following major conclusions concerning a comparison of the impact of the tested fuels (TM/135/18, $\mathrm{TM} / 136 / 18$, and TM/154/18), compared to the reference fuel (TM/134/18):

- The tested fuels (TM/135/18, TM/136/18, and TM/154/18) have no practical impact (compared to the $\mathrm{TM} / 134 / 18$ fuel) on the hourly fuel consumption (and, consequently, also on the overall efficiency of the en- 
gine). The only differences observed during the tests are within the limit of approx. $1 \%$, which is within the limit of engine operation repeatability.

- The TM/135/18 fuel has an impact on the engine operation process basically only at low engine loads. At such loads, a small reduction of the concentration of nitrogen oxides $\left(\mathrm{NO}_{\mathrm{x}}\right)$ in the exhaust gas of the engine was observed.

- The TM/136/18 fuel has a different qualitative action compared to the TM/135/18 fuel because its impact on the operating process of the engine is noticeable only at medium and high engine loads. At such loads, the concentration of $\mathrm{NO}_{\mathrm{x}}$ in the flue gas of the engine was reduced (compared to the comparative fuel TM/134/18). Because usually a reduction of $\mathrm{NO}_{\mathrm{x}}$ concentration in exhaust gas is accompanied by an increase of smoke opacity of the exhaust gas, also in this case the TM/136/18 fuel was characterized by a slightly higher smoke opacity of the exhaust gas at high engine loads (compared to the TM/134/18 fuel). Due to the small practical impact of the TM/136/18 fuel on a reduction of NOx concentration in the exhaust gas, a decision was made to use the $\mathrm{TM} / 154 / 18$ in which the concentration of the additive that shortens the $\tau_{\mathrm{sp}}$ is twice as high as the concentration in the TM/136/18 fuel.

- The TM/154/18 fuel is characterized by similar qualitative changes of the analyzed operating parameters of the engine as the TM/136/18 fuel, whereby the changes are much greater at medium and high engine loads. The impact of that fuel at lower engine loads $(0-80 \mathrm{Nm})$, with reference to the energy parameters and the composition of the exhaust gas of the engine, is negative. Only at higher loads (up to the maximum load), the additives used in that fuel start to have a positive impact on a reduction of $\mathrm{NO}_{\mathrm{x}}$ concentration in the exhaust gas of the engine (compared to the TM/134/18 fuel). Unfortunate$1 y$, in those conditions there is also an increase in the smoke opacity of the exhaust gas.

- In order to perform more in-depth analyses of the impact of the used fuel additives on the operating parameters and the composition of the exhaust gas of the engine and to determine the appropriate direction of further quantitative and qualitative changes in the fuel additive packages, one must conduct an evaluation of the engine operating process. For this purpose, the second article, titled "Influence of cetane-detergent additives into diesel fuel with RME content increased to $10 \%$ on the parameters of indicator diagrams and rate of heat release in a diesel engine," presents an analysis of the heat release speed for the tested fuel.

\section{Acknowledgements}

This Project was supported INNOCHEM/ POIR 01.02.00-000028/17.

\section{Nomenclature}

CI compression ignition

CO concentration of carbon monoxide

D smoke of exhaust gases

Gpal hourly fuel consumption
$\mathrm{HC}$ concentration of hydrocarbons

$\mathrm{NO}_{x}$ concentration of nitrogen oxides

RME rapeseed methyl ester

$\mathrm{PAH}$ polycyclic aromatic hydrocarbons

\section{Bibliography}

[1] CATON, A., HAMILTON, J. et al. Understanding ignition delay effects with pure component fuels in a single-cylinder diesel engine. Journal Engineering for Gas Turbines and Power. 2011, 133(3).

[2] CISEK, J., SZLACHTA, Z. The autoignition delay of vegetable fuels at varied air temperature inside combustion

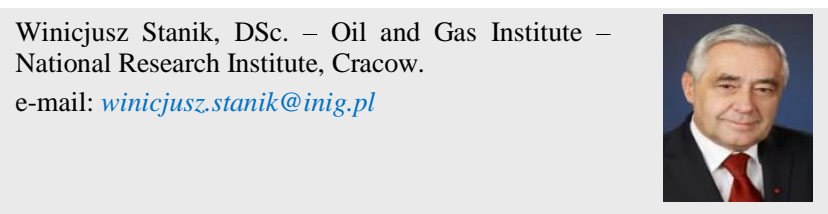

chamber of diesel engine. International Conference Agrotech Nitra 2001. Nitra, 05-6.06.2001. Slovakia.

[3] STANIK, W. Wpływ dodatku zwiększającego liczbę cetanową na właściwości zapłonowe i proces spalania oleju napędowego w silniku o zapłonie samoczynnym. Nafta-Gaz. 2017, 9, 651-659.

Jerzy Cisek, DSc., DEng. - Faculty of Mechanical Engineering, Cracow University of Technology.

e-mail: jcisek@pk.edu.pl 